\title{
Extratos vegetais: uma Alternativa à Fenolftaleína no Ensino de Química Analítica
}

\author{
Annielly F. S. Silva, Laís M. Brito \& Joyce L. da S. Gonçalves
}

Extratos etanólicos de frutas e flores foram caracterizados e avaliados como indicadores naturais de $\mathrm{pH}$ e para detecção do ponto final de titulações ácido-base. A análise qualitativa mostrou que tais extratos mudaram de cor em função do $\mathrm{pH}$ e que empregados em análise volumétrica essa mudança foi clara, rápida e satisfatória indicando o ponto final da titulação. Quantitativamente, aplicando-se análise estatística com 95\% de confiabilidade, constatou-se que esses extratos podem substituir a fenolftaleína, que é o indicador comumente empregado nesta volumetria. Sugere-se que esses extratos sejam amplamente empregados em Química Analítica, especialmente na educação básica e em cursos de licenciatura em Química devido à acessibilidade de obtenção dos espécimes naturais empregados, bem como a facilidade de manuseio dos reagentes, baixos custo, toxidez reduzida e alto potencial para instigar o espírito científico dos alunos.

Palavras Chave: indicadores; $p H$; ensino.

Extracts in ethanol of fruits and flowers were characterized and evaluated as natural $\mathrm{pH}$ indicators and use to detect the end point of acid-base titrations. The qualitative analysis showed that the extracts changed color as a function of $\mathrm{pH}$ and when they applied to volumetric analysis, such change was clear, fast and satisfactory indicating the end point of the titration. Quantitatively, applying statistical analysis by $95 \%$ of confidence, it was verified that the extracts can replace the phenolphthalein, which is the commonly indicator used in this volumetry. It is suggested that the extracts be widely used in Analytical Chemistry, especially in basic education and courses for Teaching Certificates in Chemistry due to the accessibility of the natural specimens used as well as the easily handling reagent, low cost, low toxicity and high potential to instigate the students' scientific spirit.

Keywords: indicators; $\mathrm{PH}$; education. 


\section{Introdução}

Indicadores ácido-base são substâncias que, por suas propriedades físico-químicas e estruturais, apresentam grupos cromóforos capazes de mudar de cor na presença de determinada concentração de íons $\mathrm{H}+$ (meio ácido) ou de íons OH- (meio básico) (CIDREIRA, 2011; SKOOG, et al., 2015) Os indicadores podem ser sintéticos ou naturais, e são bastante utilizados em laboratórios quando objetivase determinar o caráter ácido ou básico de uma solução ou para indicar o ponto final de uma titulação volumétrica.

Os corantes naturais vêm sendo vastamente empregados como indicadores ácido-base, como alternativa aos indicadores normalmente utilizados, como fenolftaleína, azul de bromotimol, vermelho de metila, entre outros (COUTO, RAMOS e CAVALHEIRO, 1998; COSTA, 2011). Grande parte das substâncias responsáveis pela coloração desses indicadores pertence à classe dos flavonóides.

Dentro dessa classe, as antocianinas apresentam destaque devido sua diversidade e inúmeras atividades: se encontram largamente distribuídas na natureza e são responsáveis por algumas cores, como azul, violeta e todas as tonalidades de vermelho que aparecem em flores, frutos, algumas folhas, caules e raízes de plantas (CONSTANT, 2003). Todas as antocianinas, em meio aquoso, são derivadas da estrutura básica do cátion flavilium (Figura 1). Tais substâncias demonstraram um elevado potencial de aplicação como corantes naturais, pelo fato de apresentarem diferentes tonalidades de cor, oscilando entre vermelho, laranja e roxo, de acordo com condições intrínsecas, como o $\mathrm{pH}$, temperatura e presença de oxigênio. (BROUILLARD, 1983; MAZZA e MINIATI, 1993).

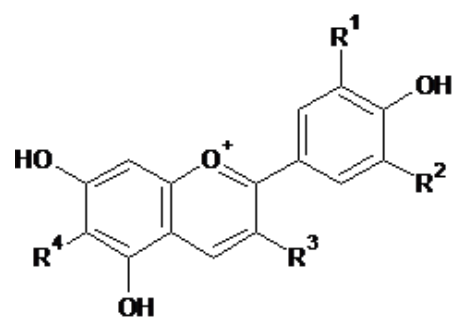

Figura 1. Estrutura básica do cátion flavilium. Fonte: (adaptado de CASTANEDA-OVANDO, et al,2009.)
Neste âmbito, o presente trabalho teve como objetivo obter e utilizar extratos etanólicos de flores e frutos como indicadores ácido-base em análises químicas. Especificamente, atribuiu-se caráter ácido ou básico às soluções comparando-se a coloração destas ao padrão de cor do extrato em meio aquoso em função do pH. Além disso, analisou-se estatisticamente a possibilidade de substituir a fenolftaleína- indicador sintético normalmente empregado, visando-se uma alternativa prática, fácil, barata e sustentável para a realização de aulas experimentais.

\section{Metodologia}

As espécies vegetais selecionadas para avaliar o potencial como indicador ácido-base na forma de extratos etanólicos foram: casca de jabuticaba (Myrciaria cauliflora Berg.), flores de hibisco (Hibiscus rosa-sinensis L.), flores de pata de vaca (Bauhinia variegata L.), casca de uva (Vitis vinifera $L$.), flores de Ixora (Ixora chinensi $L$.) e flores de vinca (Catharanthus roseus). Tais espécies vegetais foram coletadas na região do cerrado, da cidade de Piranhas-GO.

A extração de cada espécie foi obtida por maceração e imersão de $25 \mathrm{~g}$ de espécimes em $100 \mathrm{~mL}$ de álcool etílico comercial $92,8 \%$. O recipiente foi envolto por papel alumínio e mantido a $25{ }^{\circ} \mathrm{C}$ por 48 horas (adaptado de SANTOS, L.G.V. et al., 2012). Após este período, filtrouse a solução e armazenou-se o extrato em frascos de vidro protegidos da luz.

O extrato etanólico foi analisado por espectroscopia Ultravioleta-Visível, empregando um espectrofotômetro marca Perkin Elmer, modelo Lambda 25 na região do visível entre 400 a $800 \mathrm{~nm}$ para determinação do comprimento de onda de máxima absorção $(\mathrm{nm})$ da solução do extrato. Posteriormente, para análise qualitativa da aplicabilidade dos extratos como indicador ácido-base foram comparadas as cores de soluções aquosas dos extratos em função do $\mathrm{pH}$, variando-se o pH de 1,0 a 14 empregando-se indicador universal (MORITA E ASSUMPÇÃO, 2012).

Analisou-se ainda, quantitativamente, a viabilidade de aplicação desses extratos em titulações volumétricas. Para isso, transferiu-se $10 \mathrm{~mL}$ de solução de ácido clorídrico 
( $\mathrm{HCl})$ 0,1000 mol.L-1 padronizada com tetraborato de sódio como padrão primário, para um erlenmeyer de 250 $\mathrm{mL}$, e adicionou-se 10 gotas do extrato indicador à solução ácida. Em seguida, titulou-se com solução de hidróxido de sódio $(\mathrm{NaOH})$ 0,0968 mol. $\mathrm{L}^{-1}$ previamente padronizada com biftalato de potássio (MORITA E ASSUMPÇÃO, 2012; SKOOG et al., 2015), sob constante agitação, até que houvesse mudança na coloração. Com o intuito de comprovar a eficácia dos extratos na substituição pelo indicador comumente empregado, o mesmo procedimento foi realizado utilizando 3 gotas de fenolftaleína como indicador. Todas as titulações foram realizadas em triplicata. Aplicou-se o teste Q de Dixon para identificação e rejeição de valores anômalos. A análise quantitativa dos valores experimentais obtidos empregando-se os extratos vegetais e a fenolftaleína foi feita utilizando-se o intervalo de confiança para a média, com $95 \%$ de confiança (MILLER E MILLER, 2010).

\section{Resultados e Discussão}

A interação da luz com a matéria depende da estrutura química dos compostos, portanto, o espectro de absorção é uma das formas de caracterização da obtenção do extrato (Figura 2).

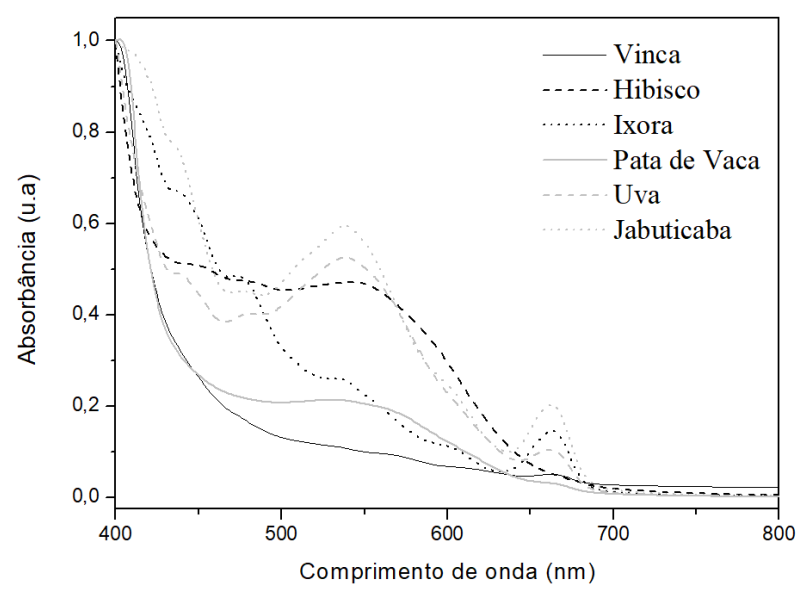

Figura 2. Espectro de absorção qualitativo dos extratos etanólicos.
Observou-se que todos os extratos apresentaram bandas de absorção no visível devido aos grupos cromóforos que possuem antocianinas em sua composição. As antocianinas são capazes de absorver fortemente na região do visível, especificamente na região compreendida entre 496 e $550 \mathrm{~nm}$ (BROUILLARD, 1982). Essa característica particular permite a quantificação das antocianinas por métodos espectrofotométricos em medições simples de absorbância em comprimentos de onda adequados (MARCO, POPPI e SCARMÍNIO, 2008).

As antocianinas apresentam cores diversas consoante com o $\mathrm{pH}$ do meio em que elas se encontram, o que facilita o seu uso como indicadores naturais de pH (TERCI E ROSSI, 2002). As soluções de antocianinas apresentam uma coloração vermelha mais intensa, em $\mathrm{pH}$ abaixo de 2,0. Quando se eleva o pH para a faixa de 5,0 a 6,0, a coloração vermelha tende a desaparecer. Aumentos adicionais de $\mathrm{pH}$ levam as antocianinas a apresentarem uma coloração azulada, as quais, após estocagem ou aquecimento, tornam-se amareladas (MAZZA E BROUILLARD,1987, CASTANEDA-OVANDO et al, 2003 ).

Neste âmbito, os resultados da análise qualitativa da aplicabilidade da solução aquosa dos extratos como indicadores de $\mathrm{pH}$ mostraram que todos os extratos adquiriram diferentes tonalidades em função do $\mathrm{pH}$ e que podem ser facilmente identificadas visualmente (DIAS, GUIMARÃES e MERÇON, 2004). Estruturalmente, as mudanças que ocorreram com a variação do $\mathrm{pH}$ alteraram a conjugação das moléculas de antocianina, acarretando no aparecimento das espécies com colorações diferentes (TERCI E ROSSI, 2002) que podem ser aplicadas em análises químicas. A Figura 3 mostra os padrões de cores dos extratos etanólicos em função do pH.

\begin{tabular}{c|cccccc}
\hline \multirow{2}{*}{ Indicador } & \multicolumn{5}{c}{ Cor em função do pH } \\
\cline { 2 - 7 } & Extrato & 1 & 2 & 6 & 10 & 14 \\
\hline Jabuticaba & & & & & & \\
Hibisco & & & & & & \\
Pata de vaca & & & & & & \\
Uva & & & & & & \\
Ixora & & & & & & \\
Vinca & & & & & & \\
\hline
\end{tabular}

Figura 3. Espectro de absorção qualitativo dos extratos etanólicos. 
Referente à viabilidade de utilização destes extratos como indicadores em volumetria de neutralização, observou-se que para todos os extratos empregados neste estudo, o ponto final da titulação foi facilmente identificado pela mudança de cor e os resultados estão ilustrados na Figura 4.

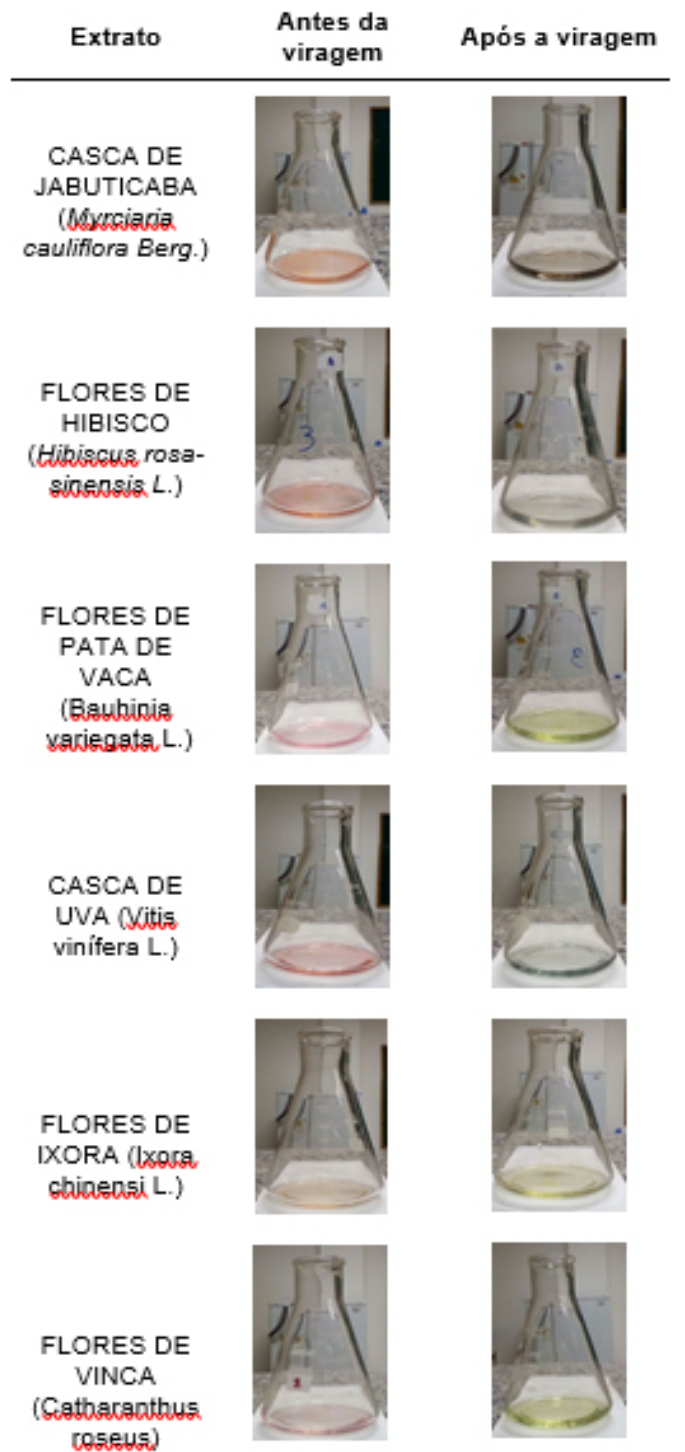

Figura 4. Soluções de $\mathrm{HCl} 0,1000 \mathrm{~mol} \mathrm{~L}^{-1}$ tituladas com $\mathrm{NaOH} 0,0968$ mol. $\mathrm{L}^{-1}$ empregando extratos etanólicos vegetais como indicadores antes e após o ponto final da titulação.
O volume médio empregado em cada titulação, bem como a concentração de $\mathrm{HCl}$ calculada em função da titulação de neutralização foram submetidos ao teste Q de Dixon para a rejeição de valores anômalos. As concentrações aceitáveis a $95 \%$ de confiança foram submetidas à comparação mediante intervalo de confiança para a média, no mesmo nível de significância (Tabela 1).

A análise estatística mostrou que a hipótese nula é aceita, considerando que os intervalos de confiança para a média dos extratos e da fenolftaleína não apresentaram diferenças significativas (MILLER E MILLER, 2010) entre a fenolftaleína e os extratos empregados neste estudo (Tabela 1). Portanto, estes extratos podem substituir a fenolftaleína em titulações de neutralização sem que existam erros referentes à leitura do volume e, consequentemente, da concentração de analito calculada a partir dessa análise química. Além disso, as flores e frutas empregadas são comumente encontradas e a preparação dos extratos é de fácil manuseio e obtenção, o que facilita o emprego destes compostos em Química Analítica.

Tabela 1. Dados de titulação e análise estatística $(n=3, p<0,05)$.

\begin{tabular}{|c|c|c|c|}
\hline Extrato & $\begin{array}{c}\text { Volume } \\
\text { médio gasto } \\
(\mathbf{m I})\end{array}$ & $\begin{array}{c}{[\mathbf{H C l}]} \\
\mathbf{( x 1 0 - 2} \\
\left.\mathbf{m o l . L ^ { - 1 }}\right)\end{array}$ & $\begin{array}{c}\text { Intervalo de } \\
\text { confiança } \\
(\mathbf{x 1 0}\end{array}$ \\
\hline Fenolftaleína & $9,75 \pm 0,05$ & $9,43 \pm 0,05$ & $9,31<\mu<9,56$ \\
\hline Jabuticaba & $9,86 \pm 0,05$ & $9,55 \pm 0,06$ & $9,41<\mu<9,69$ \\
\hline Hibisco & $9,73 \pm 0,03$ & $9,42 \pm 0,02$ & $9,35<\mu<9,50$ \\
\hline Pata de vaca & $9,63 \pm 0,02$ & $9,32 \pm 0,02$ & $9,25<\mu<9,40$ \\
\hline Uva & $9,80 \pm 0,05$ & $9,48 \pm 0,05$ & $9,36<\mu<9,60$ \\
\hline Ixora & $9,78 \pm 0,03$ & $9,47 \pm 0,02$ & $9,40<\mu<9,54$ \\
\hline Vinca & $9,60 \pm 0,05$ & $9,29 \pm 0,05$ & $9,17<\mu<9,41$ \\
\hline
\end{tabular}

\section{Conclusões}

Os resultados sugerem a utilização promissora de extratos de casca de jabuticaba (Myrciaria cauliflora Berg.), flores de hibisco (Hibiscus rosa-sinensis L.), flores de pata de vaca (Bauhinia variegata L.), casca de uva (Vitis vinifera $L$.), flores de Ixora (Ixora chinensi L.) e flores de vinca 
(Catharanthus roseus) como indicadores de pH não apenas em aulas experimentais, mas também na Química Analítica como um todo, uma vez que, foi possível empregar tais extratos como indicadores de volumetria de neutralização. A análise quantitativa mostrou que a concentração de $\mathrm{HCl}$ não apresentou diferenças significativas quando comparado os extratos vegetais ao indicador comumente usado em titulações ácido/base com 95\% de confiança.

Além disso, os extratos foram de fácil obtenção e baixo custo, sem a necessidade de empregar equipamentos sofisticados e à temperatura ambiente, o que potencializa sua utilização em locais com infraestrutura limitada e ainda instiga o espírito científico por usar materiais alternativos e do cotidiano.

\section{Agradecimentos}

Os autores gostariam de agradecer ao Laboratório de Ciências de Materiais (LabMat), de responsabilidade do professor Dr. Wagner Batista dos Santos, ao técnico de laboratório Ms. Ricardo Justino Alves e aos alunos Dário Batista Fortaleza e Kelly Aparecida da Encarnação Amorim.

\section{Referências}

1. Brouillard, R. Chemical structure of anthocyanins. In: MARKAKIS, P. Anthocyanins as Food Colors. New York: Academic Press. p.1-39, 1982.

2. Castaneda-Ovando, Pacheco-Hernandez, M., Paez-Hernandez,M. Rodriguez,J.E Galan-Vidal, A. Chemical studies of anthocyanins. Food Chemistry, 113, p.859-871, 2009.

3. Cidreira, J. S. Química Geral Experimental I: Curso Técnico em Análises Químicas, Apostila. Acidez e Basicidade. Zé Doca, 48 49p, 2011.

4. Constant, P. B. L. Extração, caracterização e aplicação em antocianinas de açaí. 200199 f. Tese (Doutorado em Ciência e Tecnologia de Alimentos)- UFV, MG, 2003.

5. Costa, K. P. O uso do açafrão da terra como indicador ácido-base no ensino de Química. 2011. 40 f., il. Monografia (Licenciatura em Química)-Universidade de Brasília, Brasília, 2011.

6. Couto, A.; Ramos, L. E Cavalheiro, E. Aplicação de Pigmentos de Flores no Ensino de Química. Química Nova. 21 (3), p. 221-227, 1998.
7. Dias, M. V.; Guimarães, P. I. C. E Merçon, F. Corantes Naturais: Extração e emprego como indicadores de $\mathrm{pH}$. Química Nova na Escola, 17, 27-31., 2003.

8. Marco, P.; Poppi, R. J.; Scarmínio, I. S. Procedimentos analíticos para identificação de antocianinas presentes em extratos naturais. Química Nova, 31 (5), p. 1218-1223, 2008.

9. Mazza, G.; Brouillard, R. Recent developments in the stabilization of anthocyanins in food products. Food Chemistry, v.25, p. 207-225, 1987.

10. Mazza, G.; Miniati, E., Anthocyanins in fruits, vegetables, and grains., London: CRC Press 1993.

11. Miller, J. N.; Miller., J.C. Statistics and chemometrics for analytical chemistry. 6ed. New York: Prentice Hall/Pearson, 2010.

12. Morita, T.; Assumpção, R. M. V. Manual de soluções, reagentes e solventes. São Paulo: Editora Blucher, 2007.

13. Santos, L.G.V; Rodrigues, L. B.; Lima, P. G.; Sousa, T. O.; Costa Neto, J. J. G.; Chaves, D. C. Indicadores naturais ácido-base a partir de extração alcoólica dos pigmentos das flores Hibiscus rosa-sinensis e Iroxa chinensi, utilizando materiais alternativos. In: Congresso Norte Nordeste De Pesquisa E Inovação, 7., 2012.

14. Skoog, D. A. W., D. M.; Holler, F. J.; Crouch, Stanley R. Fundamentos de Química Analítica, 9 ed., São Paulo-SP: Cengage Learning, 2015.

15. Terci, D.; Rossi, A. Indicadores Naturais de pH: Usar Papel ou Solução? Química Nova. 25 (4), p.684-688, 2002.
Universidade Federal de Mato Grosso, Instituto de Ciências Exatas e da Terra, Campus Universitário do Araguaia, Unidade Pontal do Araguaia: Avenida Universitária ${ }^{\circ}$ 3500. Pontal do Araguaia - MT.

*E-mail: jgoncalves@ufmt.br 